\title{
Assessment of Occupational Health and Safety Awareness among Healthcare Workers at the Pediatric Hospital in Benghazi City
}

\author{
Amal Ali Mukhtad ${ }^{*}$ Fatima Mohammed Alomamy $^{*}$ Aya Abdullah Almukassbi ${ }^{*}$ \\ Aya Joma Rafa Abbas Amira Abu baker Alfseiy
}

\begin{abstract}
Occupational health and safety (OHS) is an essential area that is concerned with the protection, health, and safety plus the welfare of individuals involved in any kind of occupation. This study aimed at assessing the occupational health and safety awareness and practices among the healthcare workers in the pediatric hospital in Benghazi city, Libya. The study adopted descriptive survey research in the Benghazi pediatric hospital. The study randomly selected 246 healthcare workers and the response rate was 96\%. A questionnaire was used as the main data collection instrument. The data were coded and analyzed using descriptive statistics; frequencies and percentages and inferential analysis of correlation. Around 50\% of the participants reported a lower level of awareness regarding occupational health and safety (OHS). The study proposes that the ministry of health should conduct specialist training in occupational health and safety for their staff, they also should confirm provisions of this policy and technical guidelines apply to all health institutions and administrative units within the health sector. Further hospital risk management should put in place a regular monitoring team who will certify that workers notice in firm terms safety measures put in place to avoid any accidents/injuries. Lastly, the study recommends that further research on the factors determining the implementation of occupational health and safety awareness and practices at public health care facilities in Libya.
\end{abstract}

Keywords: Risk, Hazard, OHS (Occupational Health and Safety), Awareness, Healthcare Facilities.

\section{Introduction}

Over the world, around 317 million accidents occur each year at workplaces causing losses where nearby 2.3 deaths increase annually resulting in production losses according to the International Labor Organization (ILO), therefore negatively impact the economy of the country at large, this can be recognized to the poor of implementation of health and safety policies (ILO, 2018). Occupational health and safety at the workplace can enhance the economy by dropping health burdens associated with it, enabling individuals to live more satisfied and longer (Cudjoe. S, 2011; Boateng \& Arthur, 2014).

*University of Benghazi, Libya. Email: amal.mukhtad@uob.edu.ly 
International Labor Organization (ILO, 2018) recommends that occupational health services are recognized near places of occupation to protect the workers against any work health-related hazards resulting in the ill health of the worker. A study conducted to evaluate the occupational health hazards among healthcare workers in Kampala, Uganda; displayed that healthcare workers work in an environment that is most hazardous due to their work-related activities (Ndegwa P, 2015).

The main goal for Occupational safety and health (OSH) is to focus on the prevention of workrelated injuries and illnesses through the providing of suitable conditions of occupation to achieve the highest level of health of all workers. This thoughtful mandate of the International Labor Organization (ILO, 2018) acts to make sure that the safety and health of workers are not ignored and that the workers do not lose occupation due to occupational illness or injury. Over the world, healthcare workers are more than 50 million and they must be protected from the many occupational hazards which they frequently face. Healthcare workers are exposed to harmful physical, chemical, and biological agents as well as violence, and musculoskeletal disorders (WHO, 2019). Occupational Safety and Health Administration (OSHA, 2018a) reported the annual rates of absenteeism allied with work-related injuries/illnesses and the likelihood of being injured in healthcare sectors are higher than in other sectors. For instance, the incidence of occupational illnesses and injuries in hospitals of the United States (US) was 68 cases per 1000 regular healthcare workers in the year 2011. Also, Healthcare-Associated Infections (HAIs) over 1.7 million and 99,000 related deaths occur annually over the world. HAIs are predictable to account for roughly $10 \%$ of hospital admissions and up to $31 \%$ in countries with controlled resources (Njogu et.al. (2019).

While the implementation of OSH policy in a workplace in terms of work risk management is the main approach for the decline of occupational safety and health problems, it is less common in healthcare sectors than in other sectors. Relevant legislation and guidelines are set up; however, a majority of institutions fail to implement them effectively. Training is a fundamental component in the management of occupational safety and health to assure and to improve understanding of the role of work risk management on performance enhancement among healthcare workers, managers, and supervisors. The management is required to realize the relevant legislation and effective $\mathrm{OSH}$ management, while healthcare workers should know occupational hazards and safe work practices. Knowledge and awareness of occupational hazards 
can contribute to safer work practices in workplaces. Then, OSH awareness can significantly make healthcare workers fit into their work by obtaining the essential skills and knowledge, and this benefits in making suitable decisions, and in the achievement and nourishment of worthy working environments (Ndegwa P, 2015; OSHA, 2018a).

\section{Statement of the Problem}

Occupational health and safety in any healthcare facility is an issue that should be dealt with a lot of concern because it provides a qualifying environment to healthcare workers in ensuring highquality performance and reduction of risks. Given the above healthcare facilities in Libya carry a large workforce drawn from different professions who need to perform their duties in sometimes overcrowded places, limited facilities, and even limited training to this awareness (Abd-el-Kader B, 2012). Some of the potential hazards are physical, chemical, biological, and psychological. And therefore Health and Safety issues relating to the personal safety and protection of its workers are a very important Environmental Health concern for hospitals (Vitayanti, F. \& Nini, A, 2017). The implementation of OSH in most health facilities in Libya is low and thus has contributed to exposure to hazards (Abd-el-Kader B, 2012). This may predict a high workload per health personnel with high exposure to the health hazards and, limited time to exercise some of the OSH practices such as hand washing, glove changing, sensitizations, and training. Also, no accurate data regard OHS is available in Libya as most of the diseases and accidents in the workplace do not come under the consideration of the labor department of the health ministry. Further, the number of occupational health physicians, nurses, and specialists is very limited compared to the entire healthcare workforce in Libya. On this basis, the $\mathrm{OH}$ system is not well recognized in the country, resulted in an insecure and unhealthy workplace. Based on the statement of the problem, the objective of the study was to assess the level of occupational health and safety (OHS) awareness and practices among the health care workers in Benghazi Pediatric Hospital, Libya during 2020.

The significance of the study is to provide awareness to HCWs about their right, progress, and encouragement of healthy and safe workplaces. It also can help in the enhancement of the physical, psychological and social well-being of HCWs and sustain for improvement and protection of their working ability. Also, provide the information on the current status of the $\mathrm{OH}$ services in the health sector and work to fix the situation of the problem because long-term productivity and high quality of services cannot be achieved in the poor working environment 
with HCWs who are presenting to health and safety threats.

Under the limitations, there were no difficulties we faced at the beginning of sample collection inside the hospital until the outbreak of the Covid-19 epidemic in a large way and all means of access to the target group were closed and many of them were afraid and avoided direct interaction, which led to a waste of our time to collect the sample and start its analysis. In addition, limited sources were found about the knowledge, attitudes, and practice of OHS in healthcare facilities in Libya.

\section{Materials and Methods}

Based on the nature of the research, the cross-sectional survey research design was applied. The study targeted 688 healthcare workers (HCWs) including physicians, nurses, technicians; in the Pediatric Hospital in Benghazi city, Libya. The sample size was estimated by using the Krejcie \& Morgan 1970, standardized table for determining sample size for the known population. Thus, the sample size was 246 however, the response rate of those targeted groups was 95\% (237 healthcare workers).

Data Collection Procedures: As a methodology, it has been used benchmarking literature accessible. This study consisted of 3 phases. Phase one involved the analysis of existing evidence and drawing up lists of work potential risks/hazards in the healthcare setting. Phase two included a questionnaire that was used by previous evidence (Cudjoe S, 2011). This questionnaire was translated to Arabic language and adapted to the Libyan environment. It was divided into 2 sections. The first section included demographic questions about gender, age, educational level, education, occupation. Section two dealt with a variety of questions regarding occupational health and safety perception including questions about knowledge, attitudes, practices, and worker's awareness as well as occupational hazards, work satisfaction, etc. The questionnaire was randomly distributed from March 1 to July 26/2020. Healthcare workers have worked for less than a year, excluded from the current study. Additionally, to ensure the reliability of the research instrument a pilot study was conducted in the hospital a month before the actual study to assess the validity of the questionnaire that was not contained within the later study. After pilot testing, the required changes were completed and adopted accordingly. Phase three, conduct a short interview with HCWs and citing responses from interviews that agreed with the findings.

Data Analysis: Data for this study was normally distributed, so quantitatively analyzed by Statistical Package for Social Sciences (SPSS) version 21. It was used to investigate quantitative 
data and descriptive statistics including frequencies and percentages and inferential analysis (correlation coefficient) was done. Tables, graphs, and charts were used in data presentation to provide visual simplicity of presented data. In addition, thematic analysis was used to analyze qualitative data and was combined with the quantitative data by mentioning responses from interviews that agreed with the results.

Ethical Considerations: There were no ethical issues, but an application for ethical acceptance was obtained from the director of the development and human resources department to collect data for voluntary participation in this study.

\section{Findings and Discussion}

Table (1) shows the demographic characteristics of the participants. The highest percentage of the total sample were females with $76 \%(n=181)$, while $24 \%(n=56)$ were males of the total sample. Regarding age categories, $46 \%(n=109)$ was ranged from $(20-30$ years $), 32 \%(n=75)$ was ranged from (31-40 years), while 19\% were more than 40 years old and 3\% were less than 20 years old. The majority of the target group $[43 \%(n=101)]$ were nurses of the total sample, followed by physicians, who were $36 \%(n=86)$, while $21 \%(n=50)$ of the total sample were technicians. Also, 46\% $(\mathrm{n}=108)$ of the respondents had a bachelor's degree, $24 \%(\mathrm{n}=57)$ had a high diploma, 21\% $(\mathrm{n}=50)$ of respondents had a high school $\backslash$ diploma and 7\% $(\mathrm{n}=18)$ had a preparatory educational level. $2 \%(\mathrm{n}=4)$ was the lowest percentage of educational level with postgraduate. It has been found that $44 \%(n=103)$ had worked in the hospital for less than five years. $29 \%(n=69)$ was practiced their works for more than 10 years and $27 \%(n=65)$ of the respondents had to experience ranged between 5 to 10 years.

Table 1. Demographic Characteristics of the Participants

\begin{tabular}{|l|c|c|}
\hline Variables & Frequency & Percent \% \\
\hline Gender & & \\
Male & 56 & 24 \\
Female & 181 & 76 \\
\hline Age & & 3 \\
<20 Year & 8 & 46 \\
20-30 Year & 109 & 32 \\
$31-40$ Year & 75 & 19 \\
$>40$ Year & 45 & 36 \\
\hline Occupation & & 43 \\
Physician & 101 & 21 \\
Nurse & 50 & \\
Technician & & \\
\hline Academic Level & & \\
Preparatory & & \\
\hline
\end{tabular}




\begin{tabular}{|l|c|c|}
\hline High School/Diploma & 18 & 7 \\
High Diploma & 50 & 21 \\
Bachelor & 57 & 24 \\
Postgraduate & 108 & 46 \\
& 4 & 2 \\
\hline Work Experience & 103 & 44 \\
$>5$ Years & 65 & 27 \\
$5-10$ Years & 69 & 29 \\
$>10$ Years & & \\
\hline
\end{tabular}

$(\mathbf{n}=\mathbf{2 3 7})$

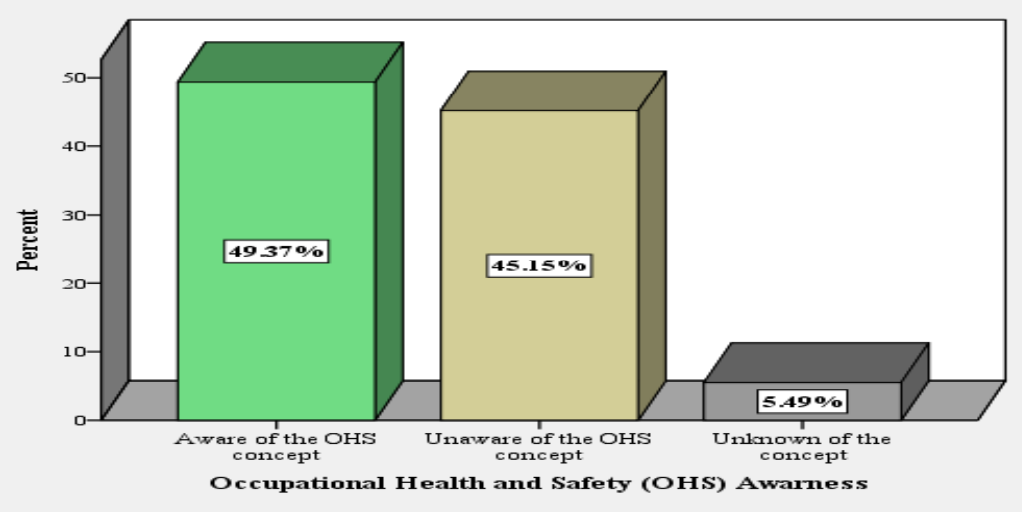

Figure 1: Awareness Regarding Concept of Occupational Health and Safety (OHS)

Around $49 \%(n=117)$ of the study participants have aware of the concept of occupational health and safety (OHS), while about $45 \%(n=107)$ have unaware of the concept of OHS and the rest $5.5 \%(n=13)$ have unknown of this concept as presented in Figure 1. Also, a study in Iraq displayed that around $50 \%$ of the respondents, described the lower level of OHS awareness (Shakhawan A \& Shareef O., 2019). However, 84\% of respondents reported that healthcare workers were very aware of OHS awareness (ILO, 2018)

In Nigeria, a study aimed to determine the level of knowledge, attitude, and practice among healthcare workers, where $89 \%$ were aware of the OSH and only $11 \%$ were not aware (Costa et.al., 2013). Thus, the lack of conducting OHS training programs for healthcare workers at the Benghazi pediatric hospital can be one of the main causes of the lower level of OHS awareness.

Table 2. Current Occupational Health and Safety Measures

\begin{tabular}{|l|c|c|}
\hline OHS Measures for Healthcare Workers & Frequency & $\mathbf{\%}$ \\
\hline Immediate reporting of accidents/injuries & 21 & 9 \\
\hline Provide a medical record and a medical periodic examination & 6 & 2.5 \\
\hline $\begin{array}{l}\text { Provide a vaccination program (before and during the } \\
\text { profession) }\end{array}$ & 13 & 5.5 \\
\hline Regular monitoring and evaluation of workplace risks/ & 5 & 2 \\
\hline
\end{tabular}




\begin{tabular}{|l|c|c|}
\hline hazards: Ensuring compliance with OHS measures & 11 & 5 \\
\hline $\begin{array}{l}\text { Training on health and safety in the work environment is an } \\
\text { essential part before starting work }\end{array}$ & 43 & 18 \\
\hline Using protective clothing & 53 & 22 \\
\hline Conduct all the OHS measures & 85 & 36 \\
\hline Do not conduct any OHS measures & & \\
\hline
\end{tabular}

$(n=237)$

Besides, Table 2 displays the current occupational health and safety procedures in the hospital. $36 \%(n=85)$ of the participants reported that they did not conduct any of the OHS measures mentioned, while $22 \%(\mathrm{n}=53)$ of the participants reported conducting all OHS procedures listed in the questionnaire, $18 \%(n=43)$ mentioned only wearing protective clothing, and $9 \%(n=21)$ informed that immediate reporting of accidents and injuries was conducted, and $5 \%(\mathrm{n}=11)$ confirmed that involved in a training program about OHS on regular basis, $2.5 \%(\mathrm{n}=6)$ reported the provision of a medical record and periodic medical examination, and only $2 \%(\mathrm{n}=5)$ mentioned that there were regular monitoring and evaluation of workplace hazards. In contrast, evidence has a high level of OHS practices as $86 \%$ of the target group complied with PPE use (Shakhawan A \& Shareef O., 2019). The reason for the improper use of PPE was the lack of knowledge toward its protection and the lack of obligation.

Moreover, a low percentage of the participants reported the vaccination as the current OHS measures at the Benghazi pediatric hospital. Evidence determined hospital nurses' knowledge levels regarding occupational health and safety and found $91 \%$ have got vaccinated as the vaccination is considered as one of the basic OHS measures conducting at their healthcare facilities (Singh B \& Ghatala M 2012).

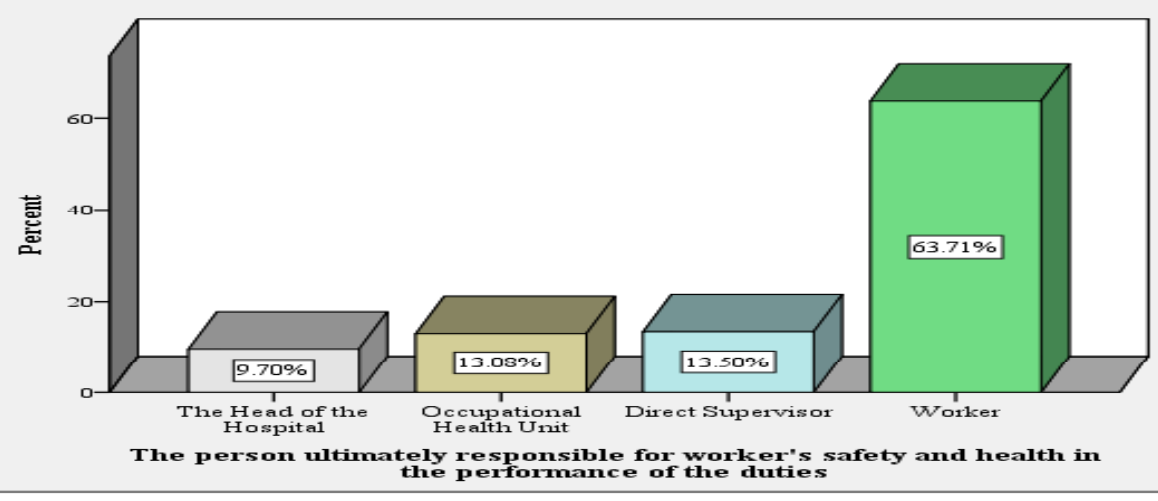

Figure 2: Who are Responsible for Occupational Health and Safety during Duties 
Figure 2 illustrates healthcare workers' awareness to investigate who are responsible for their occupational health and safety during their duties. Approximately 64\% $(n=151)$ of those participants reported that workers who were responsible for protecting themselves during performing duties, while $13.5 \%(\mathrm{n}=32)$ reported that supervisor who has responsibility for protecting workers during performing duties, whereas $13.1 \%(n=31)$ of those targeted showed that occupational health unit was responsible for the protection and approximately $10 \%(\mathrm{n}=23)$ informed that the head of the hospital was responsible for providing a safe work environment for workers.

Table 3. Accident/Injury Exposure at Work

\begin{tabular}{|l|c|c|}
\hline & Frequency & \% \\
\hline Accident/Injury Exposure (n=237) & 104 & \\
Yes & 133 & 56 \\
No & & \\
\hline Accident/Injury Risk Factors (n=104) & 23 & 22 \\
Un compliance with occupational health and safety measures & 31 & 30 \\
Lack of adequate training on occupational health and safety & 41 & 39 \\
Lack of proper personal protective equipment & 9 & 9 \\
Work stress/Workload & & \\
\hline Accident/Injury Reporting & 75 & \\
Yes & 29 & 28 \\
No & & \\
\hline Occupational Health and Safety Department at the Hospital & 85 & 36 \\
(n=237) & 41 & 17 \\
Yes & 111 & 47 \\
No & & \\
Unknown & & \\
\hline
\end{tabular}

Table 3 shows accident/injury exposure at work. 65\% $(n=133)$ of participants did not mention any work accident/injury exposure. However, 44\% $(n=104)$ of participants stated that they had work accident/injury exposure. The study was found that $72 \%$ of the respondents were confirmed immediate work accident/injury reporting (Cudjoe S, 2011). 39\% $(n=41)$ of the participants had an accident/injury risk factor due to the lack of proper personal protective equipment. 30\% $(n=31)$ informed that they had also an accident/injury risk factor because of a lack of training on OHS. $22 \%(n=23)$ reported that they had an accident/injury risk due to un compliance with occupational health and safety OHS) measures listed before in table two. 9\% $(n=9)$ mentioned that they had work stress/workload. $72 \%(n=75)$ of participants reported the occurrence of accident/injury. On the other hand, the evidence presents that $64 \%$ of 38 respondents stated that 
work accidents resulted in work stress and physical and verbal abuse respectively (Bett et.al, 2019). $47 \%(n=111)$ of the participants did not know if there was an OHS department inside the hospital or not. $36 \%(n=85)$ confirmed the presence of the OHS department inside the hospital while $17 \%(n=41)$ of the participants answered: there is no OHS department in the pediatric hospital in Benghazi. Bett et.al (2019) shows that most of the respondents were aware of the occupational risks they are exposed to as $88 \%$ of the respondents agreed that there are occupational accidents in their health facilities.

The current study was intended to find out from participants who they think is ultimately responsible for their health and safety at the workplace during performing duty, representing $63 \%$ indicated that occupational health and safety is more of an individual staff member's responsibility than management, supervisors or any other person, department or unit. This can justify the reason for not complying with safety preventive measures. It also explains why $47 \%$ of those participants did not aware of the existence of the Occupational Health and Safety Department inside the hospital. It has been seen that the provision of OHS services may be limited particularly, in conducting work risk management. Evidence agreed with this outcome as more than half of the respondents declared that the hospital does not conduct work risk management in its organizational structure (Shakhawan A \& Shareef O., 2019). It clears that occupational health and safety (OHS) measures did not properly apply on-site.

The healthcare workers in Benghazi pediatric hospital who have reported work accidents/injuries exposure stated some causes of the accidents/injuries: lack adequate of training on health and safety, failure to track instructions on the use of tools and equipment, no provision of necessary protective clothing and equipment and ignorance on health and safety matters. However, the majority of the study participants (75\%) stated that providing a safe work environment has positive effects on the quality of work performance. This result was consistent with a study that aims to assess the knowledge of nurses on occupational health and safety measures in the hospital (Sanaei Nasab H et al., 2009).

Table 4. Training Program for Workers

\begin{tabular}{|l|c|c|}
\hline & Frequency & \% \\
\hline Conducting the OHS Training Program (n=237) & & \\
Yes & 71 & 30 \\
No & 166 & 70 \\
\hline
\end{tabular}




\begin{tabular}{|l|c|c|}
\hline If yes, how regular is training organized $(\mathbf{n}=\mathbf{7 1})$ & 5 & 7 \\
Quarterly & 12 & 17 \\
Biannually & 11 & 15 \\
Annually & 43 & 61 \\
No definite fixed time & & \\
\hline Conducting the First Aid Program (n=237) & 85 & 36 \\
Yes & 152 & 64 \\
No & \\
\hline
\end{tabular}

Table 4 shows the training program for healthcare workers in the pediatric hospital. $70 \%(\mathrm{n}=166)$ of the participants did not involve any OHS training program. $61 \%(n=43)$ of them said "training has no fixed time", 17\% $(\mathrm{n}=12)$ supposed training was twice a year. 15\% $(\mathrm{n}=11)$ supposed was annually, and the rest 7\% $(n=5)$ informed, training was quarterly. But, the majority [64\% $(n=152)]$ of the participants reported that they did not conduct any first aid program.

Regarding the conducting of training program at work in specific OHS training and first aid program, it has been noticed in the current study that the percentage of participants who did not receive both training programs about work safety and first aid were high. It can be seen that though the hospital organizes a few training on health and safety, this process is not implemented on regular basis. Staff needs to be aware of training schedules on health and safety and share fully in it. A study was conducted in public health facilities in Kenya that aimed to determine (OSH) and awareness among healthcare workers. These facilities conducted work safety training program for their workers on regular basis, following the Occupational Safety and Health Law in states of Kenya, that it requires the employer to ensure the provision of training and necessary information on occupational safety and health for all persons in the workplace (Kaguathi J, 2013; Ndejjo et al., 2015; Yesilgul Ci, 2018).

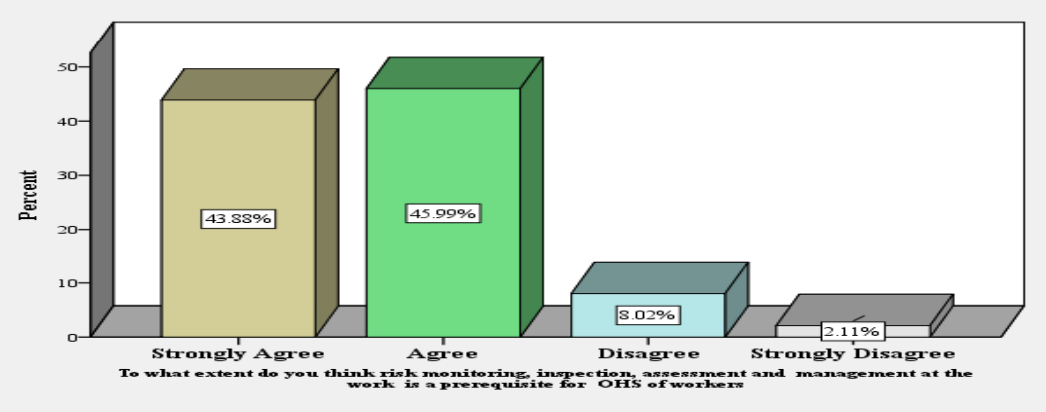

Figure 3: Importance of Risk Assessment and Management at the Work 
Figure 3 represents the important role of risk assessment and management at the work. Most participants have confirmed the essential role of conducting work risk management on the worker's performance. $46 \%(\mathrm{n}=109)$ of the participants agreed that risk assessment and management at the hospital are necessary whereas nearly $44 \%(n=104)$ also strongly agreed. The rest of the participants disagreed.

Table 5. Improvement of the Level of Work Risk Management at the Hospital

\begin{tabular}{|l|c|c|}
\hline Risk Management Actions/Procedures & Frequency & \% \\
\hline $\begin{array}{l}\text { Involve a safety expert to redesign the hospital's occupational health } \\
\text { and safety policies }\end{array}$ & 3 & 1 \\
\hline Training Worker to report any health and safety risks/hazards at work & 18 & 7.5 \\
\hline Training workers to report work injury/accident & 16 & 7 \\
\hline Training on Quick response during work injury/Accident & 18 & 7.5 \\
\hline Training for wearing PPE & 24 & 10 \\
\hline Conduct all of the above actions & 54 & 23 \\
\hline Handling Work stress/Avoid Violence & - & - \\
\hline No Actions & 104 & 44 \\
\hline Total & 237 & 100 \\
\hline
\end{tabular}

Regard the improvement level of work risk management at the hospital as presented in Table 5, $44 \%(n=104)$ of the participants stated with no improvement in the level of work risk management while $23 \%(n=54)$ informed that all the above OHS actions were received whereas $10 \%(n=24)$ received only training for donning and doffing PPE, about $7.5 \%(n=18)$ for both of accident/injury reporting and hazard/risk reporting. On other hand, all participants reported that there was not any risk assessment/management for handling work stress and violence.

Figure 4: Worker Awareness Regarding Reducing the Level of Risks at Work

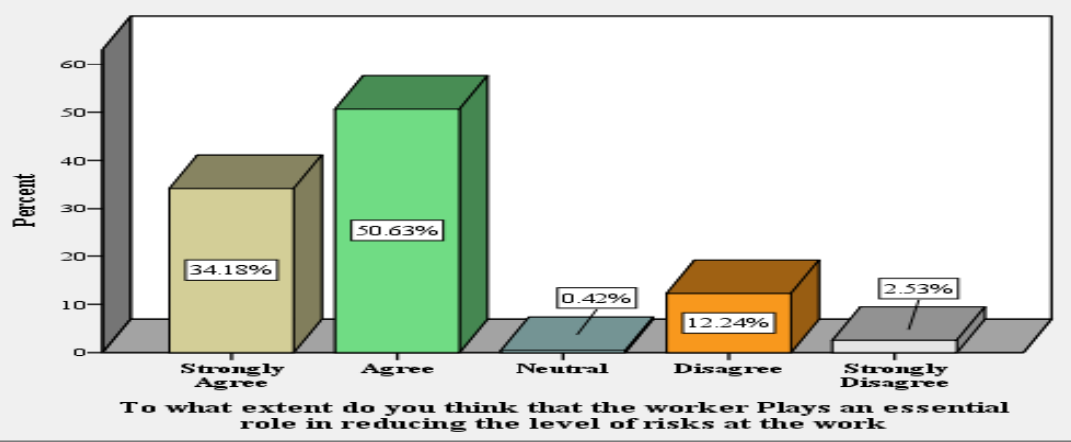

Figure 4 demonstrates the worker awareness regarding reducing the level of risks at the work. It 
has been found that the highest percent of the total sample were agreed $50.6 \%(n=120)$, strongly agree were $34.2 \%(\mathrm{n}=81)$, followed by disagreeing $12.2 \%(\mathrm{n}=29), 4 \%(\mathrm{n}=1)$ was a natural, followed by strongly disagree $2.5 \%(n=6)$ of the total sample.

Table 6. Positive Impacts of Conducting Work Risk Management on the Quality of the Work Services

\begin{tabular}{|l|c|c|}
\hline Variables & $\mathbf{N}$ & $\mathbf{\%}$ \\
\hline Provide a safe work environment have a positive impact on the quality of & & \\
work performance & 175 & 74 \\
Yes & 20 & 8 \\
No & 42 & 18 \\
Unknown & & \\
\hline Positive Impacts on The Quality of Health Services & 62 & 26 \\
Labor turnover is reduced & 5 & 2 \\
The corporate image of the hospital is enhanced & 22 & 9 \\
Improves the quality of health services for patients & 3 & 1.3 \\
Raise the employee's job satisfaction level & 11 & 5 \\
Reduces absenteeism rates from work & 1 & 0.4 \\
Reduces cost of compensation to injured workers & 8 & 3 \\
Reduces accidents and injuries & 3 & 1.3 \\
Reduces risks of worker loss or death & 122 & 52 \\
All of the above & & \\
\hline Total & 237 & 100 \\
\hline
\end{tabular}

Table 6 shows the positive impacts of conducting work risk management on the quality of health services. Although $18 \%(\mathrm{n}=42)$ did not know how a safe workplace can positively affect the quality of health performance, $74 \%(n=175)$ of the participants agreed that providing a safe work environment has a positive impact on the quality of work performance. Also, $26 \%(n=62)$ of the participants supposed that the reduction of labor turnover was the most important positive effect of conducting work risk management. $9 \%(n=22)$ stated that can improve the quality of health services for patients. $5 \%(n=11)$ supposed that can reduce work absenteeism rates and $3 \%(n=8)$ also supposed that can reduce accidents and injuries. Only three healthcare workers supposed that can raise the employee's job satisfaction level and reduce risks of worker loss or death. Accordingly, 52\% $(n=122)$ of the participants listed all the above positive impacts. The majority of them were ranged from strongly agree to agree that point of view as they showed conducting work risk assessment and management are a crucial requirement for effective occupational health and safety. But, studies were argued that the staffs agree that there cannot be effective health and 
safety if monitoring, inspection, and evaluation are carried out. (Cudjoe S, 2011) (Yesilgul Ci, 2018) (Kipruto Be, 2019).

The study participants presented in their opinions that effective occupational health and safety policies can have an impact positively on job performance in the hospital. The current study participants indicated the success as the benefits the hospital and workers develop from effective occupational health and safety policies including decreases accidents, decreases the cost of compensation to injured employees, loss or death of a worker, labor turnover is reduced, and corporate image of the hospital is improved. These findings were also displayed in several studies (Cudjoe S, 2011; Makala, 2011; Yesilgul Ci, 2018; Njogu et.al., 2019).

Figure 5: Guidelines on Occupational Health and Safety at the Hospital

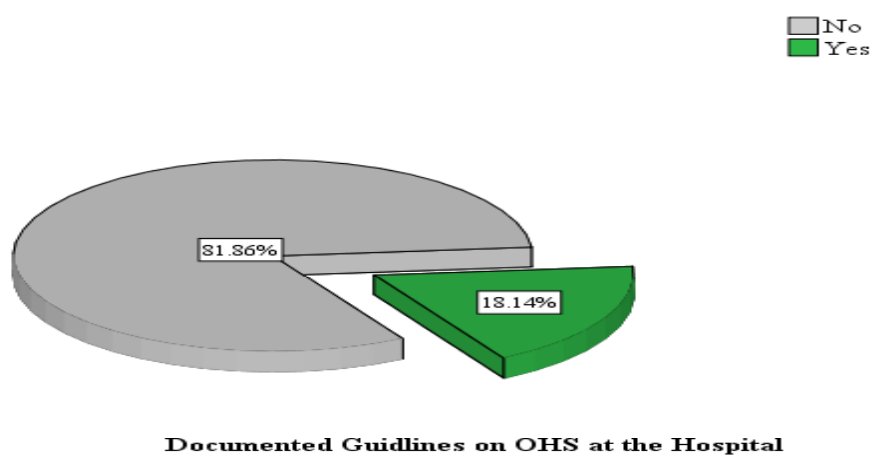

Figure 5 illustrates a pie chart of provision documented guidelines on occupational health and safety (OHS) in the hospital. Most of the participants [81.9\% $(\mathrm{n}=194)]$ stated no provision whereas $18.4 \%(n=43)$ were stated yes. In a study conducted in Kenya, designed to determine the level of OHS awareness among workers in the field of health public clinics and health centers, 48.8\% mentioned having OHS documented guidelines (Njogu et.al., 2019).

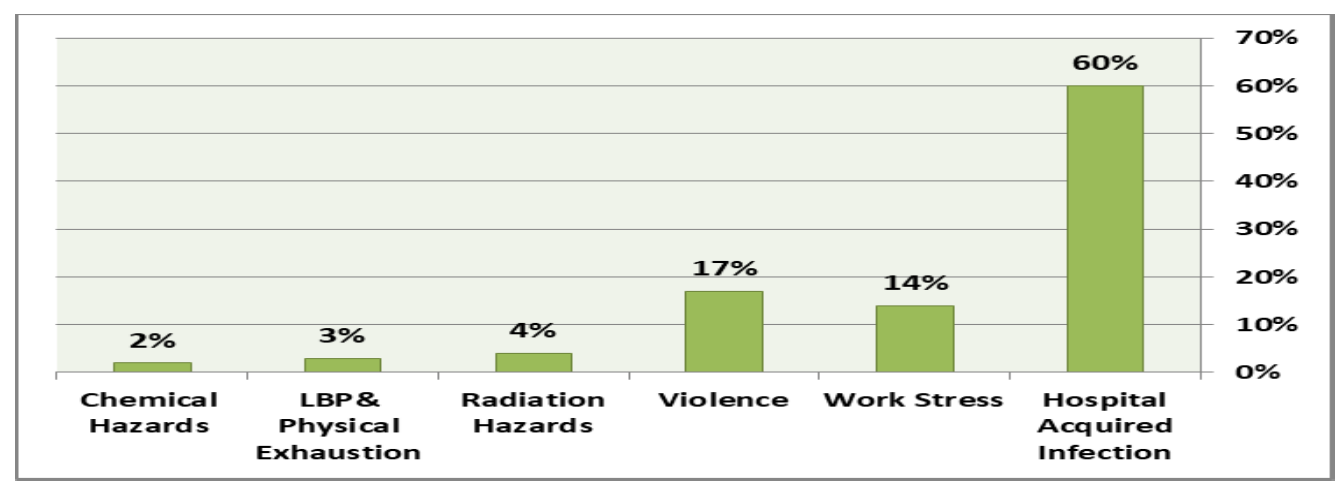

Figure 6: Types of Occupational Hazards 
This Bar chart (Figure 6) shows common types of occupational hazards at the pediatric hospital. The results indicate that $50.6 \%$ of those targeted were aware of the level of occupational hazards and risks. It is clear that the highest risk exposure to the healthcare workers in the Benghazi pediatric hospital was reported hospital-acquired infection, which was agreed with evidence that indicated the highest level risk exposure of the healthcare workers in Nicosia, Cyprus was bloodborne diseases (Yesilgul Ci, 2018). On the other hand, radiation risk exposure was reported very low at the Benghazi pediatric hospital, while the respondents in a study were conducted in Nicosia, Cyprus, reported high concern towards risk exposure to radiation, back pain (22\%), and physical exhaustion (71.5\%) and workplace violence (Yesilgul Ci, 2018). The percentage of the perception of the healthcare workers in Benghazi Pediatric hospital regard back pain and physical fatigue were weak where the violence was $17 \%$. It can be seen that the limited knowledge regard occupational hazards and risks can increase the exposure to them during the duties. Thus, adopting and evaluating the role of OHS in terms of work risk management can significantly improve the quality of health services.

Table 7. Correlations between Work Experience and Occupational Health and Safety Awareness

\begin{tabular}{|c|c|c|c|c|}
\hline & & & $\begin{array}{c}\text { Work } \\
\text { Experience }\end{array}$ & $\begin{array}{c}\text { OHS } \\
\text { Awareness }\end{array}$ \\
\hline \multirow[t]{6}{*}{$\begin{array}{l}\text { Spearman's } \\
\text { rho }\end{array}$} & \multirow[t]{3}{*}{ Work Experience } & $\begin{array}{l}\text { Correlation } \\
\text { Coefficient }\end{array}$ & 1.000 & .080 \\
\hline & & Sig. (2-tailed) & & .220 \\
\hline & & $\mathrm{N}$ & 237 & 237 \\
\hline & \multirow[t]{3}{*}{ OHS Awareness } & $\begin{array}{l}\text { Correlation } \\
\text { Coefficient }\end{array}$ & .080 & 1.000 \\
\hline & & Sig. (2-tailed) & 220 & \\
\hline & & $\mathrm{N}$ & 237 & 237 \\
\hline
\end{tabular}

Table 7 describes the correlations between work experience and occupational health and safety awareness. There was a weak direct correlation between awareness of health and occupational safety and practical experience and its value was (0.080) and it has been noticed that the probability value was greater than $(0.025)$, so it can say that the association was not significant morally. 
Table 8. Correlations between Work Experience, Satisfaction Regarding the Current OHS Preventive Measures and Satisfaction Regarding the Current Risk Management

\begin{tabular}{|c|c|c|c|c|c|}
\hline & & & $\begin{array}{c}\text { Work } \\
\text { Experience }\end{array}$ & $\begin{array}{l}\text { Satisfaction } \\
\text { regard the } \\
\text { current } \\
\text { OHS } \\
\text { preventive } \\
\text { measures }\end{array}$ & $\begin{array}{l}\text { Satisfaction } \\
\text { regard the } \\
\text { current risk } \\
\text { Management }\end{array}$ \\
\hline \multirow[t]{3}{*}{$\begin{array}{l}\text { Spearman's } \\
\text { rho }\end{array}$} & Work Experience & $\begin{array}{l}\text { Correlation } \\
\text { Coefficient } \\
\text { Sig. (2-tailed) } \\
\text { N }\end{array}$ & $\begin{array}{r}1.000 \\
. \\
237\end{array}$ & $\begin{array}{r}-0.47- \\
.475 \\
237\end{array}$ & $\begin{array}{r}-0.61- \\
.348 \\
237\end{array}$ \\
\hline & $\begin{array}{l}\text { Satisfaction regard } \\
\text { the current OHS } \\
\text { preventive measures }\end{array}$ & $\begin{array}{l}\text { Correlation } \\
\text { Coefficient } \\
\text { Sig. (2-tailed) } \\
\mathrm{N}\end{array}$ & $\begin{array}{r}-.047- \\
.475 \\
237 \\
\end{array}$ & $\begin{array}{r}1.000 \\
. \\
237 \\
\end{array}$ & $\begin{array}{r}-.344-^{* *} \\
.000 \\
237 \\
\end{array}$ \\
\hline & $\begin{array}{l}\text { Satisfaction regard } \\
\text { the current risk } \\
\text { Management }\end{array}$ & $\begin{array}{l}\text { Correlation } \\
\text { Coefficient } \\
\text { Sig. (2-tailed) } \\
\text { N }\end{array}$ & $\begin{array}{r}-.061- \\
.348 \\
237\end{array}$ & $\begin{array}{r}-.344-^{* *} \\
.000 \\
237\end{array}$ & $\begin{array}{r}1.000 \\
237\end{array}$ \\
\hline
\end{tabular}

**. Correlation is significant at the 0.01 level (2-tailed).

Table 8 shows the correlation coefficients between work experience and satisfaction concerning the current preventive measures for occupational health and safety satisfaction concerning current risk management were weak inverse relationship coefficients and from the probability values, we find that the correlation coefficients have no significant effect.

Additionally, $44 \%$ of the study participants had work experience for more than 5 years. There was a weak direct correlation between awareness of occupational health and safety and work experience so the association was not significant. However, a study reported that $44 \%$ of the healthcare workers practiced work during 1-5 years. It was found that there was a significant and statistically significant correlation between years of experience and the level of perception about occupational health and safety (Shakhawan A \& Shareef O, 2019).

Table 9. Correlations between Educational Level and OHS Awareness 


\begin{tabular}{|lll|r|r|}
\hline & & $\begin{array}{c}\text { Educational } \\
\text { Level }\end{array}$ & \multicolumn{1}{c|}{$\begin{array}{c}\text { OHS } \\
\text { Awareness }\end{array}$} \\
\hline $\begin{array}{l}\text { Spearman's } \\
\text { rho }\end{array}$ & Educational Level & Correlation & 1.000 & $-.211-^{* *}$ \\
& & Coefficient & & .001 \\
& & Sig. (2-tailed) & 237 & 237 \\
& & $\mathrm{~N}$ & $-.211^{* *}$ & 1.000 \\
& & Correlation & .001 & \\
& OHS Awareness & Coefficient & 237 & 237 \\
& & Sig. (2-tailed) & & \\
& & $\mathrm{N}$ & & \\
& & &
\end{tabular}

**. Correlation is significant at the 0.01 level (2-tailed).

It clears that Table 9 shows the correlation between (educational level) and (occupational health and safety awareness) which was a weak reverse correlation and its value $(-0.211)$ so this probability value was less than $(0.025)$. It can say that the correlation was significant.

Table 10. Correlations between conducting Occupational Health and safety training program and accident/injury exposure.

\begin{tabular}{|c|c|c|c|c|}
\hline & & & $\begin{array}{c}\text { Accident/Injury } \\
\text { Exposure }\end{array}$ & $\begin{array}{c}\text { OHS } \\
\text { Training } \\
\text { Program }\end{array}$ \\
\hline \multirow[t]{4}{*}{$\begin{array}{l}\text { Spearman's } \\
\text { rho }\end{array}$} & $\begin{array}{l}\text { Accident/Injury } \\
\text { Exposure }\end{array}$ & $\begin{array}{l}\text { Correlation } \\
\text { Coefficient } \\
\text { Sig. (2-tailed) }\end{array}$ & 1.000 & $-.003-$ \\
\hline & & $\mathrm{N}$ & 237 & 237 \\
\hline & $\begin{array}{l}\text { OHS Training } \\
\text { Program }\end{array}$ & $\begin{array}{l}\text { Correlation } \\
\text { Coefficient } \\
\text { Sig. (2-tailed) }\end{array}$ & $-.003-$ & 1.000 \\
\hline & & $\mathrm{N}$ & 237 & 237 \\
\hline
\end{tabular}

It has been found from Table 10 that there was a weak inverse correlation between (OHS training) and (accident exposure) and its value (-0.003). Also, the probability value was greater than $(0.025)$, so the correlation was not significant morally. 
Table 11. Prevention of OHS Risks/Hazards

\begin{tabular}{|l|c|c|c|c|}
\hline & Frequency & Percent & $\begin{array}{c}\text { Valid } \\
\text { Percent }\end{array}$ & $\begin{array}{c}\text { Cumulative } \\
\text { Percent }\end{array}$ \\
\hline Valid Yes & 237 & 100 & 100 & 100 \\
\hline
\end{tabular}

The participants were additionally asked whether the occupational safety health risks/hazards that are exposed to are preventable and all the participants approved on the preventability. From the interview plan the participants indicated that occupational hazards/risks could be prevented by approving that medical examinations are done frequently in the hospital, risk assessment in this hospital, strict implementation of health rules and regulations, confirming that warning signs are indicated and labeled in the hospital. Dagbah G, (2011) identified that the promotion of health interventions that significantly can lead to the prevention of injury confirmed higher levels in productivity in the organizations under study.

\section{Conclusion}

It can be concluded that the healthcare workers in Pediatric hospitals in Benghazi city, Libya reported their exposure to many occupational hazards including hospital-acquired infection, violence, work stress, and others. These hazards can have a great impact on their health and their work performance so the lack of conducting OHS training programs for healthcare workers at the Benghazi pediatric hospital was considered as one of the main causes of the lower level of OHS awareness among healthcare workers because the low level of awareness of OSH was (45\%) among those workers about risks and hazards they were exposed to at work. Thus more training programs, seminars, and workshops are required to bridge the gap noticed from healthcare workers who had no OSH awareness.

The worker in the health sector plays an essential role in providing health services in hospitals. To ensure these services become at the satisficing level they are required to be worked in a safe work environment, avoiding work hazards and risks that can negatively impact the healthcare settings. Accordingly, workers need to comply with all health and safety rules, knowing that the person ultimately responsible for his/her health and safety is himself/herself. They are also required to wear protective clothing, use equipment and tools provided for their work, and report any accidents/injuries. Accidents can be costly both to the affected worker and the organization. Therefore, every effort should be made to avoid them from happening in the workplace. The study recommended that a responsible organization should be focused on conducting an OSH management process that involves the steps of risk assessment and recommended as well as 
implemented control measures with emphasis on continual improvement in terms of the monitoring work environment and reviewing the steps of risk assessment and management. Further depth researches on the factors determining the implementation of occupational health and safety OHS awareness and practices at public health care facilities in Libya should be conducted.

\section{References}

Abd-el-Kader, B. (2012). Evaluation the performance of the healthcare services in hospitals in Benghazi city, Libya. Unpublished Research Working Paper.

Boateng, J \& Arthur, Y. (2014). Influence of risk management practices on service quality in health care delivery. Journal of Economics and Sustainable Development, 5(14): 176-185

Costa, V, Meirelles, B \& Erdmann, A. (2013). Best practice of nurse managers in risk management, south of Brazil. Revista Latino-Americana de Enfermagem, 21(5):1165-1171

Cudjoe, S. (2011). An assessment of occupational health and safety practices on job performance at the Tetteh Quarshie Memorial Hospital, Mampong-Akuapem, Ghana. Published Research Working Paper. Retrieved from http://citeseerx.ist.psu.edu/viewdoc/download?doi=10.1.1.829.7352\&rep=rep1\&type=pdf

Dagbah, G. (2011). Internal control as a toll for financial management in the public sector: A case study of Ges, Adaklu-Anyigbe District, Ghana. Masters' Thesis, Kwame Nkrumah University of Science and Technology, Kumasi Ghana.

International Labor Organization (2018). Safety and health at work: International Labor Office (ILO): Geneva.

Kipruto, B. (2019), Assessment of occupational safety and practices in public health facilities in Kenya. IOSR Journal of Dental and Medical Science, 18(8):42-50.

Makala. (2011). Assessment of occupational safety and health awareness and practices in public health facilities, in public policy at the University of Witwatersrand. PAMJ (38):76-22.

Ndegwa, P. W. (2015). Perceptual measures of determinants of implementation of occupational safety and health programs in the manufacturing sector in Kenya (Doctoral dissertation).Retrieved from http://hdl.handle.net/123456789/1703

Njogu, P. Mburu, C \& Karanja, B. (2019). Role of safety and health awareness in occupational safety and health performance in public health facilities in Machakos country, Kenya. Journal of Health and Environmental Research, 5 (1): 1-7.

Occupational Safety and Health Administration (2018a). Safety and health management systems: Facts about hospital worker safety- New York: U.S. Department of Labor.

Sanaei Nasab, H. Tavakoli, R. Ghofranipour, F. Kazemnejad, A \& Khavanin, A.(2009). Evaluation of knowledge, attitude and behavior of workers towards occupational health and safety. Iran J Public Health, 38(2):125-129.

Shakhawan, A \& Shareef, O. (2019). Assessment of occupational health and safety measures knowledge and experienced types of hazards among nursing staff in Rania Hospital. Erbil j. Nurs. Midwifery, 2(2): 39-43 
Singh, B \& Ghatala, MH. (2012). Risk management in hospitals. International Journal of Innovation, Management and Technology, 3(4): 417-421.

Ndejjo, R. Musinguzi, G. Yu, X. Buregyeya, E. Musoke, et.al. (2015). Occupational health hazards among healthcare workers in Kampala, Uganda. $J$ Environ Public Health, (5):741-913.

Vitayanti, F. \& Nini, A. (2017). The effect of control environment, risk assessment, control activities, information and communication and monitoring on fraud prevention in the local government of Palu, Indonesia. Russian Journal of Agriculture and Socio-Economic Sciences, 5(65):181-191.

World Health Organization (2019). Health worker occupational health. In: WHO (Ed.) Occupational Health Workers, Volume 2012. Geneva: WHO.

Yesilgul, Ci. (2018). Nurses' knowledge levels and perceptions regarding occupational risks and hazards in Kenya. International Journal of Caring Sciences, 11(2):1117-1122 